\title{
Influência do tipo de ácido usado e da sua concentração na ativação de uma argila bentonítica
}

\section{(Influence of the type and concentration of the used acid on the activation of bentonite clays)}

\author{
E. L. Foletto ${ }^{1}$, C. Volzone ${ }^{2}$, A. F. Morgado ${ }^{I}$, L. M. Porto ${ }^{I}$ \\ ${ }^{1}$ Departamento de Engenharia Química e Engenharia de Alimentos \\ Universidade Federal de Santa Catarina, C. P. 476, 88040-900, Florianópolis, SC. \\ ${ }^{2}$ Centro de Tecnología de Recursos Minerales y Cerámica \\ C.C. 49, Cno Centenario y 506 (1897) M. B. Gonnet, Prov. Buenos Aires, Argentina.
}

\begin{abstract}
Resumo
A ativação ácida de uma argila tem por finalidade aumentar as suas propriedades adsortivas e catalíticas. Nesse estudo, uma amostra de argila bentonítica, proveniente da Província de Mendoza (Argentina), foi ativada com diferentes concentrações $(4$ e $8 \mathrm{~N}$ ) por ácido sulfúrico e clorídrico. Para verificar a influência das concentrações e do tipo de ácido usado na ativação da argila, utilizou-se técnicas de difração de raios $\mathrm{X}$, análise térmica diferencial e termogravimétrica e análise química. Os resultados mostraram que houve modificação na estrutura do material argiloso após o ataque ácido. O tratamento com ácido sulfúrico e clorídrico sobre uma mesma bentonita originou produtos com diferentes características estruturais.
\end{abstract}

Palavras-chave: ativação ácida, argila, bentonita.

\begin{abstract}
The clay acid activation has the purpose of increasing its adsorbent and catalytic properties. In this study, a bentonite clay sample from Mendoza (Argentine) was activated in different concentrations ( $4 N$ and $8 N$ ) through the use of sulphuric and hydrochloric acid. To verify the influence of concentrations and the kind of acid utilized in the clay activation, it was utilized techniques of X-ray diffraction, thermogravimetric and differential thermal analysis and chemical analysis. The results have shown that the clay structure was modified after acid attack. Sulphuric and hydrochloric acid treatment in the same bentonite originated products with different structural characteristics.
\end{abstract}

Keywords: acid activation, clay, bentonite.

O objetivo deste trabalho é analisar as modificações estruturais desenvolvidas na bentonita após tratamento por ácido clorídrico e sulfúrico em duas diferentes concentrações.

\section{EXPERIMENTAL}

Foi utilizada uma amostra bentonítica natural (denominada W), provinda da Província de Mendoza (Argentina), como material de partida para a realização dos ensaios de ativação ácida. A argila natural seca e moída foi passada totalmente em peneira 200 mesh.

Para os ensaios de ativação, tratou-se, sob agitação mecânica, uma quantidade de bentonita em ácido a $10 \%(\mathrm{p} / \mathrm{v})$ a $90{ }^{\circ} \mathrm{C}$, sob refluxo, durante duas horas. Utilizou-se solução de ácido sulfúrico e clorídrico nas concentrações de $4 \mathrm{~N}$ e $8 \mathrm{~N}$. Os sólidos obtidos após esse tratamento foram lavados e posteriormente colocados para secar a $55{ }^{\circ} \mathrm{C}$ por 24 horas. O material sólido seco foi desagregado e peneirado até se obter frações menores que 200 mesh. As amostras ativadas foram designadas de WS4, WS8, WC4, WC8, onde "S" e "C" correspondem ao ácido sulfúrico e clorídrico, 
respectivamente.

Os difratogramas de raios $\mathrm{X}$ (DRX) foram obtidos com um equipamento Philips 3020, com controlador PW3710, usando radiação de $\mathrm{Cu}-\mathrm{K} \alpha(\lambda=1,5405 \AA)$ com filtro de $\mathrm{Ni}$ a $40 \mathrm{kV}$ e $20 \mathrm{~mA}$. A velocidade angular foi de $1^{\circ}(2 \theta) / \mathrm{min}$.

As curvas da análise térmica diferencial (DTA) e termogravimétrica (TG) foram obtidas com o equipamento Netzsch STA 409 com uma razão de aquecimento de $10^{\circ} \mathrm{C} / \mathrm{min}$, operando em atmosfera de ar seco $(35 \mathrm{~mL} / \mathrm{min})$, na faixa de temperatura de $25-1000{ }^{\circ} \mathrm{C}$.

Foi utilizado um equipamento Philips PW-2400 para a determinação, por fluorescência de raios $\mathrm{X}$, da composição química das amostras bentoníticas.

\section{RESULTADOS E DISCUSSÃO}

A Fig. 1 mostra os difratogramas de raios $\mathrm{X}$ da bentonita original. Foi possível detectar esmectita, quartzo, feldspato, caulinita e gesso na amostra. De todos os componentes, a esmectita e a caulinita são classificados como argilas, sendo a esmectita o principal componente argiloso presente nas bentonitas. A bentonita foi fracionada em tamanho menor que $2 \mu \mathrm{m}$ para analisar a fração argila, e o difratograma correspondente a essa amostra fracionada se encontra na mesma figura, na qual é possível observar uma maior concentração de esmectita.

Para certificar-se da presença de argila esmectítica na bentonita, foi realizada análise de DRX nas amostras orientadas, calcinadas a $500{ }^{\circ} \mathrm{C}$ (por 4 horas) e solvatadas com etileno glicol, cujos difratogramas são apresentados na Fig. 2. Os resultados da amostra indicam que efetivamente se tem uma resposta característica de esmectitas, ou seja, o espaçamento basal d(001) expande a 16,95 quando as amostras são glicoladas e contrai a 9,70 $\AA$ quando são calcinadas a $500{ }^{\circ} \mathrm{C}[8]$.

$\mathrm{Na}$ Tabela I são apresentados os valores da razão entre a intensidade do pico da esmectita $\mathrm{d}(001)$ e do quartzo $(2 \theta=26,6)$ obtidos a partir dos difratogramas de raios $\mathrm{X}$ das amostras natural e ativadas, mostrados na Fig. 3. Observa-se que as amostras atacadas com ácido súlfúrico apresentam razões menores do que às atacadas com ácido clorídrico, indicando que a modificação estrutural foi maior quando se utilizou ácido sulfúrico. $\mathrm{Na}$ mesma tabela são

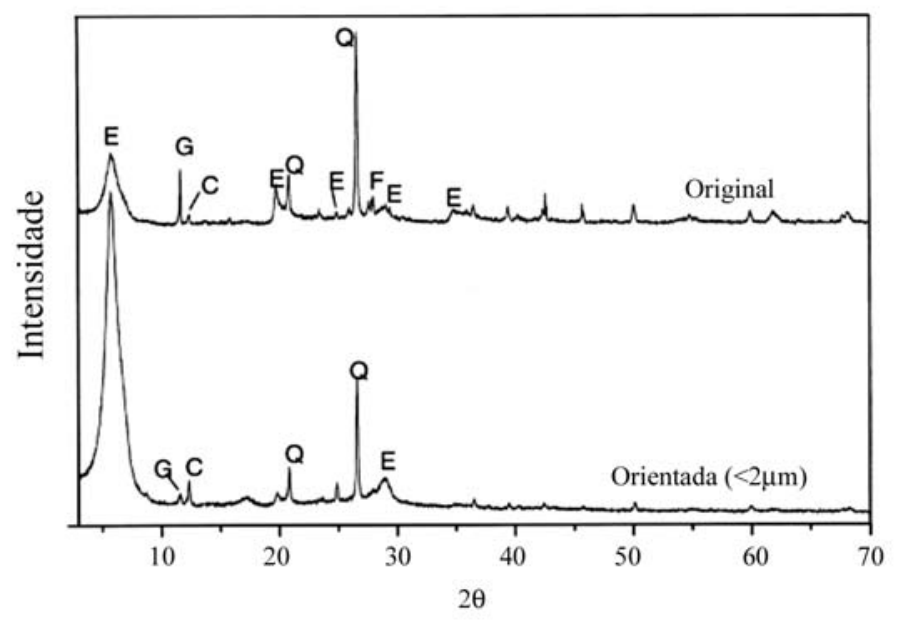

Figura 1: Difratogramas das amostras original e orientada $(<2 \mu \mathrm{m})$. $(\mathrm{E}=$ esmectita, $\mathrm{C}=$ caulinita, $\mathrm{Q}=$ quartzo, $\mathrm{F}=$ feldspato, $\mathrm{G}=$ gesso).

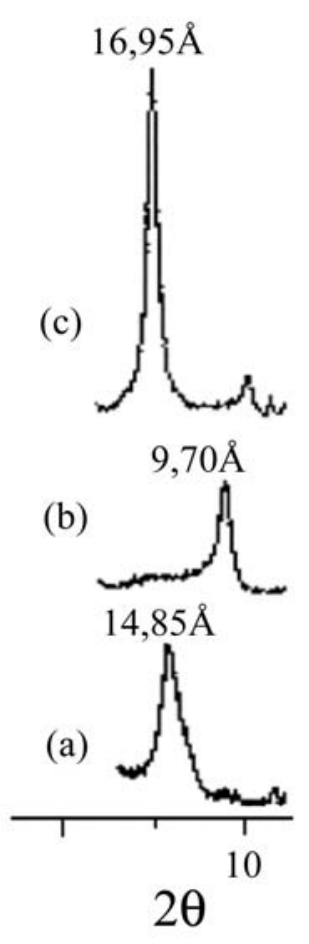

Figura 2: Espaçamento d(001) da amostra natural orientada (a), calcinada a $500{ }^{\circ} \mathrm{C}$ (b) e glicolada (c).

mostrados os valores de espaçamentos interlamelares e pode-se observar que o tratamento com ácido sulfúrico origina espaçamentos menores $(13,83$ e $12,94 \AA)$ que o tratamento com clorídrico $(15,85$ e 15,09 $\AA$ ), indicando uma maior proximidade entre as camadas da estrutura, quando se utiliza o primeiro ácido.

$\mathrm{Na}$ Fig. 4 encontram-se as curvas DTA das amostras natural e ativadas. As curvas DTA mostram que o tratamento ácido modifica notavelmente o pico endotérmico correspondente à perda de água adsorvida (a cerca de $150^{\circ} \mathrm{C}$ ) e os picos correspondentes à perda de hidroxilas estruturais $\left(525\right.$ e $\left.695^{\circ} \mathrm{C}\right)$. Pode-se observar ainda, através das curvas DTA, que os picos relativos à perda de hidroxilas das amostras ativadas ocorrem a menores temperaturas e com diminuição na intensidade quando comparados com os da amostra original, indicando que o tratamento ácido vai tornando o material menos estável termicamente.

Na Tabela II são apresentados os valores da perda de peso (\%) decorrentes da eliminação da água, calculados a partir das curvas

Tabela I - Razão entre a intensidade do pico da esmectita d(001) e do quartzo (26,6 $\AA$ ) para as amostras natural e ativadas, obtida através da análise de DRX.

\begin{tabular}{lcc}
\hline Amostra & Esmectita d(001) & $\begin{array}{c}\text { I d(001) esmectita / } \\
\text { I quartzo }(2 \theta=26,6)\end{array}$ \\
\hline W (bruta) & 14,90 & 0,31 \\
\hline WC4 & 15,85 & 0,17 \\
\hline WC8 & 15,09 & 0,12 \\
\hline WS4 & 13,83 & 0,13 \\
\hline WS8 & 12,94 & 0,08 \\
\hline
\end{tabular}




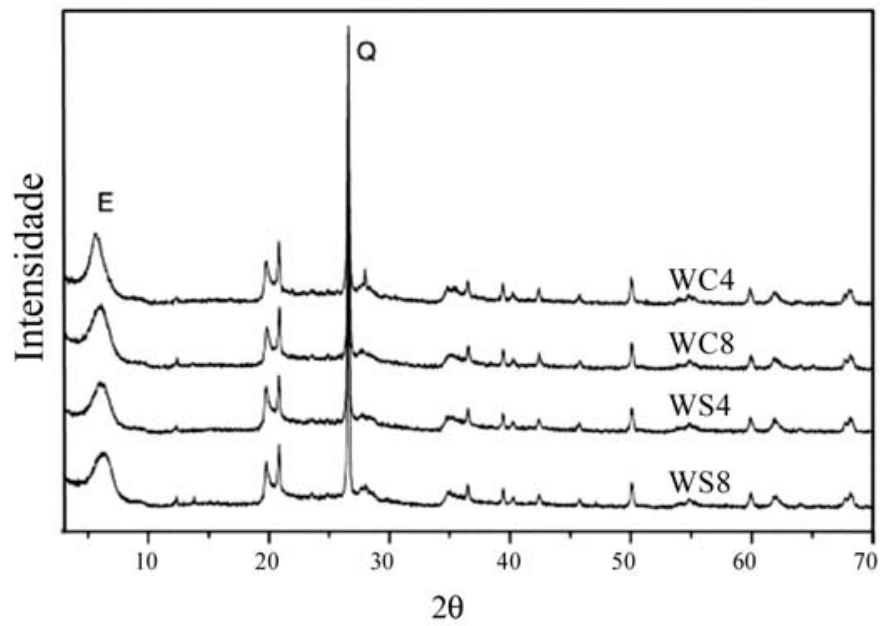

Figura 3: DRX das amostras natural e ativadas $(\mathrm{E}=$ esmectita, $\mathrm{Q}=$ quartzo).

Tabela II - Porcentagem da destruição da folha octaédrica obtida a partir das curvas TG.

\begin{tabular}{lcc}
\hline Amostra & $\begin{array}{c}\text { Perda de peso na } \\
\text { desidroxilação (\%) }\end{array}$ & $\begin{array}{c}\text { \% calculada da } \\
\text { destruição da folha } \\
\text { octaédrica }\end{array}$ \\
\hline W & 3,28 & - \\
\hline WC4 & 2,89 & 11,89 \\
\hline WC8 & 2,79 & 14,94 \\
\hline WS4 & 2,80 & 14,63 \\
\hline WS8 & 2,61 & 20,42 \\
\hline
\end{tabular}

TG (Fig. 5) das amostras natural e atacadas, no intervalo de temperaturas de desidroxilação (temp. inicial $=450{ }^{\circ} \mathrm{C}$ e temp. final $=750{ }^{\circ} \mathrm{C}$ ). A Tabela II também apresenta a porcentagem da destruição da folha octaédrica, provocada pelo ataque ácido, calculada pela diminuição da perda de peso no intervalo de temperaturas de desidroxilação, com relação às perdas sofridas nessa região pela amostra não atacada.

Todas as amostras atacadas apresentam de 11,89 a 20,42\% da folha octaédrica destruída. $\mathrm{O}$ maior ataque à estrutura bentonítica ocorre quando se utiliza ambos os ácidos na maior concentração

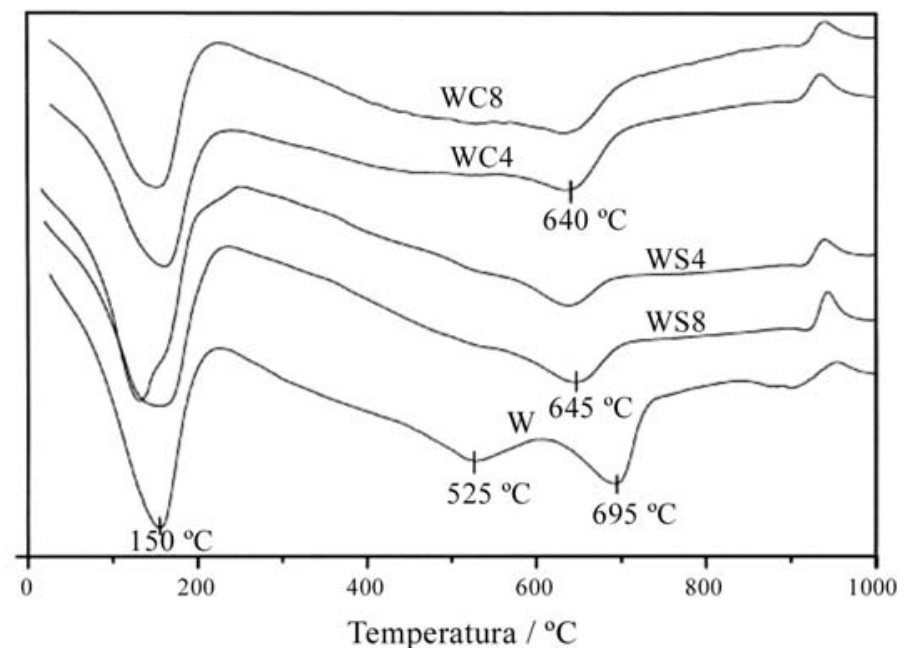

Figura 4: Curvas DTA das amostras natural e ativadas.

$(8 \mathrm{~N})$, entretanto os tratamentos realizados utilizando ácido sulfúrico 4 e $8 \mathrm{~N}$ indicam maior destruição da folha octaédrica (14,63 e $20,42 \%$ ) quando comparados com os tratamentos realizados com ácido clorídrico na mesma concentração, 4 e 8N (11,89 e 14,94\%).

A Tabela III apresenta a composição química das amostras natural e tratadas com ácido clorídrico e ácido sulfúrico. As quantidades de $\mathrm{Ca}^{+2}, \mathrm{Na}^{+}$e $\mathrm{K}^{+}$que foram removidas pelo tratamento correspondem aos cátions trocáveis que estão presentes nas amostras. No entanto, uma quantidade considerável desses elementos permanece nas amostras ativadas devido à presença de impurezas, principalmente o feldspato, que é insolúvel em soluções ácidas e que contém esses cátions [9]. Observou-se também uma importante redução dos cátions octaédricos (alumínio, ferro e magnésio) com a ativação. Os valores da relação sílica/óxidos octaédricos das amostras WS4 e WS8 foram maiores que os correspondentes às amostras WC4 e WC8, indicando que as primeiras sofreram maiores modificações em suas estruturas.

A partir dos dados da Tabela II, calculou-se a quantidade de cátions octaédricos removidos em cada amostra ativada nas diferentes condições em relação à quantidade de cátions presentes na amostra original. Esses valores estão ilustrados na Fig. 6. Observa-se que as amostras ativadas com ácido súlfurico apresentam uma maior destruição estrutural, o que corrobora os resultados da porcentagem de destruição da folha octaédrica, apresentados na Tabela II.

Tabela III - Composição química das amostras.

\begin{tabular}{lccccccccccc}
\hline Amostra & $\mathrm{SiO}_{2}$ & $\mathrm{Al}_{2} \mathrm{O}_{3}$ & $\mathrm{Fe}_{2} \mathrm{O}_{3}$ & $\mathrm{MgO}$ & $\mathrm{Na}_{2} \mathrm{O}$ & $\mathrm{CaO}$ & $\mathrm{K}_{2} \mathrm{O}$ & $\mathrm{TiO}_{2}$ & $\mathrm{MnO}$ & $\mathrm{PF}$ & $\mathrm{R}$ \\
\hline $\mathrm{W}$ & 65,18 & 17,51 & 4,53 & 1,18 & 2,24 & 1,57 & 0,86 & 0,42 & 0,08 & 6,24 & 2,80 \\
\hline $\mathrm{WC} 4$ & 71,46 & 15,88 & 3,78 & 0,79 & 0,62 & 0,24 & 0,77 & 0,41 & 0,01 & 6,04 & 3,49 \\
\hline $\mathrm{WC} 8$ & 72,91 & 15,31 & 3,48 & 0,71 & 0,58 & 0,18 & 0,66 & 0,40 & 0,01 & 5,76 & 3,74 \\
\hline $\mathrm{WS} 4$ & 71,55 & 15,75 & 3,65 & 0,75 & 0,60 & 0,25 & 0,77 & 0,41 & 0,01 & 6,25 & 3,55 \\
\hline $\mathrm{WS} 8$ & 73,24 & 15,03 & 3,23 & 0,65 & 0,62 & 0,21 & 0,62 & 0,39 & 0,01 & 5,99 & 3,87 \\
\hline
\end{tabular}

PF: Perda ao fogo a $1000{ }^{\circ} \mathrm{C}$.

R: Razão $\mathrm{SiO}_{2} /\left(\mathrm{Al}_{2} \mathrm{O}_{3}+\mathrm{Fe}_{2} \mathrm{O}_{3}+\mathrm{MgO}\right)$ 


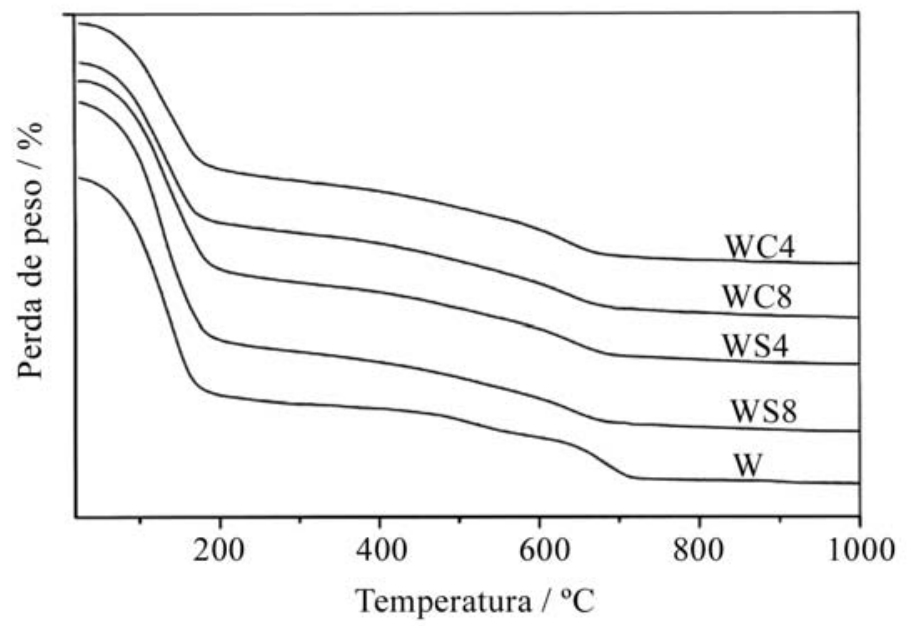

Figura 5: Curvas TG das amostras natural e ativadas.

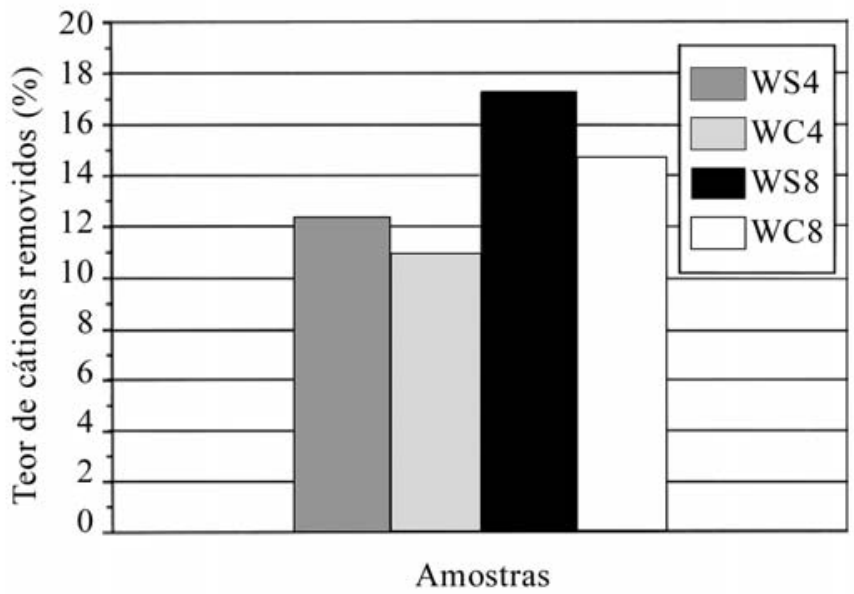

Figura 6: Quantidade (em \%) total de cátions extraídos $\left(\mathrm{Mg}^{2+}+\mathrm{Al}^{3+}+\mathrm{Fe}^{2+/ 3+}\right)$ após a ativação da bentonita com $\mathrm{HCl}$ e $\mathrm{H}_{2} \mathrm{SO}_{4}$ em diferentes normalidades.

Tabela IV - Análise comparativa do efeito do ataque à estrutura da bentonita através das diferentes técnicas de caracterização.

\begin{tabular}{llll}
\hline Amostra & DRX $^{1}$ & DTA $^{2}$ & AQ $^{3}$ \\
\hline W (bruta) & 0,31 & 3,28 & 0,00 \\
\hline WC4 & 0,17 & 2,89 & 10,87 \\
\hline WC8 & 0,12 & 2,79 & 14,65 \\
\hline WS4 & 0,13 & 2,80 & 12,29 \\
\hline WS8 & 0,08 & 2,61 & 17,25 \\
\hline
\end{tabular}

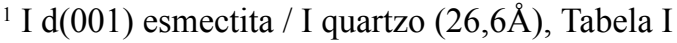

$2 \%$ Perda de peso na desidroxilação, Tabela II

$3 \%$ Cátions extraídos $\left(\mathrm{Mg}^{2+}+\mathrm{Al}^{3+}+\mathrm{Fe}^{2+/ 3+}\right)$, Fig. 4

Através da Tabela IV é possível verificar que as três técnicas de análise demonstram que o tratamento com ácido súlfúrico deteriora mais a amostra bentonítica do que o tratamento com ácido clorídrico.

\section{CONCLUSÕES}

O tratamento da bentonita com ácido sulfúrico originou um produto com maior modificação estrutural comparado ao tratamento com ácido clorídrico, trabalhando em iguais condições operacionais. Essas observações foram obtidas pelo uso das técnicas de DRX, análise química e análises térmicas.

A remoção dos cátions estruturais aumentou com o aumento da concentração ácida utilizada.

O tratamento com ácido sulfúrico provocou uma ataque de 13,5 e $17,7 \%$ maior que o tratamento com clorídrico, para concentrações de 4 e $8 \mathrm{~N}$, respectivamente, de acordo com os resultados de análises químicas.

\section{AGRADECIMENTOS}

À Susana Conconi do Centro de Tecnología de Recursos Minerales y Cerámica (Argentina), pela realização das análises DTA-TG. À CAPES, pelo auxílio financeiro do trabalho. Ao Centro de Tecnologia de Cerâmica (CTC), Criciúma-SC, pelas análises químicas.

\section{REFERÊNCIAS}

[1] T. S. G. Bhat, K. Prakash, V. J. Raksh, Evolution of porosity and surface acidity in montmorillonite clay on acid activation, Ind. Eng. Chem. Res. 34 (1995) 1440-1448.

[2] G. M. Clarke, Special Clays, Ind. Miner. (1985) 25-51.

[3] W. P. Jr. Hettinger, Contribution to catalytic cracking in the petroleum industry, Appl. Clay Sci. 5 (1991) 445-468.

[4] C. N. Rhodes, D. R. Brown, Catalytic activity of acid-treated montmorillonite in polar and non-polar reaction media, Catal. Lett. 24 (1994) 285-291.

[5] G. E. Christidis, P. W. Scott, A. C. Dunham, Acid activation and bleaching capacity of bentonites from the islands of Milos and Chios, Aegean, Greece, Appl. Clay Sci. 12 (1997) 329-347.

[6] E. L. Foletto, C. Volzone, A. F. Morgado, L. M. Porto, Modificação estrutural de bentonitas e sua utilização como agente descorante, IV Coloquio Latinoamericano de Fractura y Fatiga, Neuquén, Argentina, CD ROM (2000) 1081-1086.

[7] E. L. Foletto, C. Volzone, A. F. Morgado, L. M. Porto, Preparação de bentonitas ácidas para uso no descoramento do óleo de soja, Anais de resumos do III Encontro Brasileiro Sobre Adsorção, Jaboatão dos Guararapes-PE (2000), p. 32.

[8] G. W. Brindley, G. Brown, Crystal Structure of Clay Minerals and their X-Ray Identification, London: Mineralogical Society (1980).

[9] M. S. Barrios, L. V. F. Gonzáles, M. A. V. Rodríguez, J. M. M. Pozas, Acid activation of a palygorskite with $\mathrm{HCl}$ : development of physico-chemical, textural and surface properties, Appl. Clay Sci. 10 (1995) 247-258.

(Rec. 28/02/01, Ac. 14/11/01) 